\title{
An Aerodynamic Calculation Model for Anti-Torque System of NOTAR
}

\author{
Chen CHEN*, Han CHENG**, Peng SUN***, Changchun ZHOU**** \\ *Aviation Engineering Institute, Civil Aviation Flight University of China, Guanghan 618307, Sichuan, China, \\ E-mail: chenchen_echo@163.com \\ **Aviation Engineering Institute, Civil Aviation Flight University of China, Guanghan 618307, Sichuan, China, \\ E-mail: chenghanstorm@sina.com \\ ***Aviation Engineering Institute, Civil Aviation Flight University of China, Guanghan 618307, Sichuan, China, \\ E-mail: stewen1981@163.com \\ ****Aviation Engineering Institute, Civil Aviation Flight University of China, Guanghan 618307, Sichuan, China, \\ E-mail: 676879758@qq.com
}

cross ref http://dx.doi.org/10.5755/j01.mech.24.2.19740

\section{Introduction}

The anti-torque system, including tail boom with slots and thruster, of NOTAR (no tail helicopter) offers lateral force to balance rotor anti-torque during hover and low speed forward flight, see in Fig. 1. Air is suctioned into the tail boom by the inside variable pitch fan through flow inlet on the upper fuselage. Then, a part of the air jets from narrow slots, tangential to the boom surface to form wall jet flow, which meets the rotor wake and forms circulation control effect to provide a part of the lateral force. The rest of air flow jets from thruster at the end of tail boom and produces the other part of lateral force. The aerodynamic analysis on anti-torque system is a difficult and topical point for NOTAR [1].

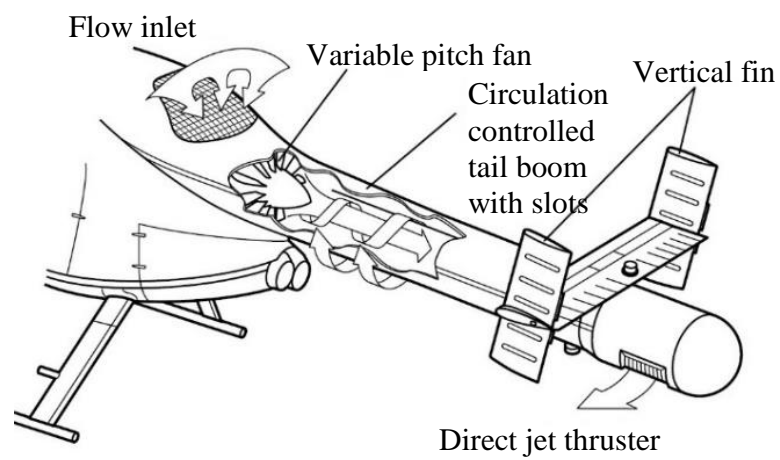

Fig. 1 Working principle of anti-torque system of a NOTAR

At present, researches on anti-torque system were mainly divided into experimental study and numerical study. The representative experimental works were mainly focused on aerodynamic characteristics on circulation controlled (CC) tail boom. Vernard [2] tested on circulation control effect on anti-torque system and gave parameter influence including position and angle of slots on lateral force coefficient. Fabrizio [3] divided the flow field into outer flow field and inner one. Then tested isolate to get their fitted empirical formulas curve. Luo [4] and Zhang [5] tested on slotted tail boom under fixed flow in wind tunnel and measured parameter influence on anti-torque system. However, the experimental methods need a lot of financial and material resources, more importantly, there existed difficulties in data collection and the results were greatly influenced by external environments. The numerical methods, which have advantages of economy and repeatability, have gradually become an important method on this subject. Henry [6] gave position of separation point based on experiment and proposed a method to calculate inner and outer flow field separately of the tail boom. However, the initial data of iteration was based on experiment, which made the method hardly to use on pre-research and design of CC tail boom. Holz [7] proposed a two-dimensional method to analyse aerodynamic characteristics of cross section of the tail boom and verified that with two slots, the tail boom gain more stable control appearance. Further, Holz [8] established an improved two-dimensional Baldwin-Lomax model to calculate aerodynamic characteristics of wall jet flow over slots. Gross [9] applied RANS, DNS and LES model to calculated Conada effect on a two-dimensional wall jet circular cylinder. Because of confidentiality and other reasons, the other researches on NOTAR were rarely reported. Most of the above numerical researches were limited to two-dimensional models, focused on only CC tail boom or wall jet instead of considering the aerodynamic characteristics of the whole anti-torque system. What's more, the influence of rotor wake was rarely considered in above works.

To overcome the limitations of referred numerical research, this paper proposed a new three-dimensional model with momentum source to calculate aerodynamic characteristics of anti-torque system. The model abandoned the traditional two-dimensional modelling methods to 'set' the jet velocity of slots but 'calculating' the interaction between components, which was more close to reality. Then the model was applied to calculate the variation rule of lateral force coefficient with the momentum coefficient and verified by experimental data. Finally, the parameter influence on anti-torque system, including length of tail boom, area of nozzle and fan pressurization was calculated.

\section{Mathematical model}

To avoid the complicated dynamic meshes on the rotor blades, momentum source method was established in this paper [10]. The procedure is shown in Fig. 2.

\subsection{Establish the coordinate system}

Establish the computational domain Cartesian coordinate $O_{1}(X, Y, Z)$, rotor disk Cartesian coordinate $O_{2}(\zeta$, 
$\eta, n)$ and rotor disk cylindrical coordinate $O_{3}(R, \varphi, n) . O_{c}$ $\left(X_{c}, Y_{c}, Z_{c}\right)$ was the origin of rotor disk domain under computational domain coordinate, shown in Fig. 3. In Fig. 3, A was left tilt angle and $B$ was back tilt angle of rotor, so $A=B=0$ in hover. The rotor inflow was $V_{\infty}$ and rotor rotating speed was $\Omega$.

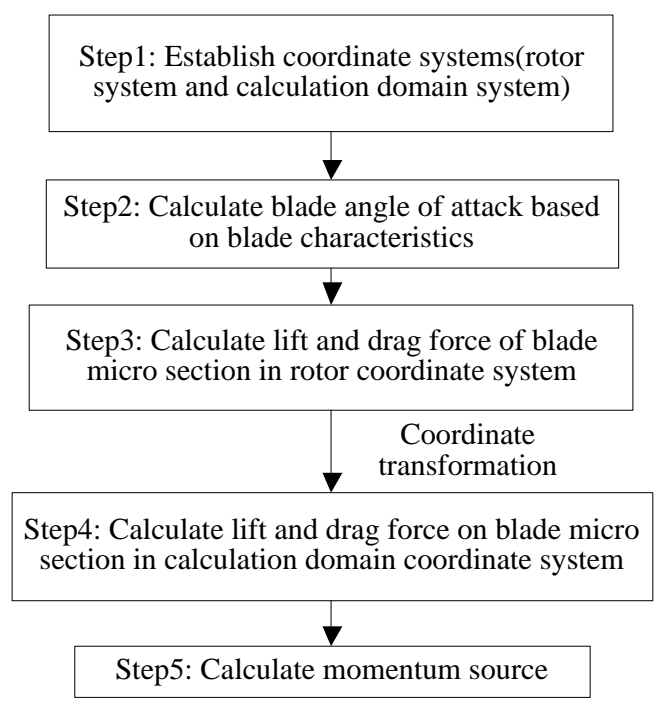

Fig. 2 Calculation procedures of momentum source

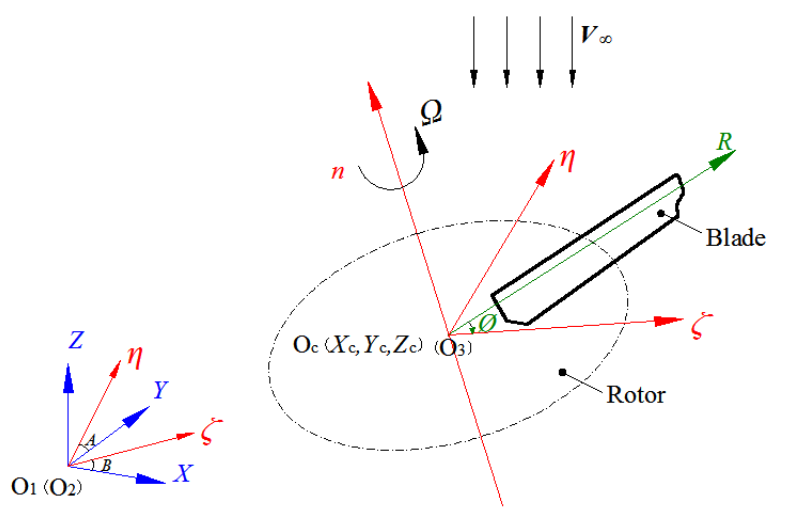

Fig. 3 Computational domain Cartesian coordinate and rotor disk coordinate

Thus, coordinate transformation equation of computational domain coordinates and rotor disk Cartesian coordinate was:

$$
\begin{aligned}
& {\left[\begin{array}{l}
\varsigma \\
\eta \\
n
\end{array}\right]=\mathrm{T}\left[\begin{array}{c}
X-X_{C} \\
Y-Y_{C} \\
Z-Z_{C}
\end{array}\right],} \\
& \mathrm{T}=\left[\begin{array}{ccc}
\cos B & \sin A \sin B & -\cos A \sin B \\
0 & \cos A & \sin A \\
\sin B & -\sin A \cos B & \cos A \cos B
\end{array}\right] .
\end{aligned}
$$

\subsection{Calculate the angle of attack $\alpha$ of the blade element}

The blade was divided into numerous blade elements based on blade element theory. Lift and drag forces were calculated on every element in rotor disk Cartesian coordinate, shown in Fig. 4.

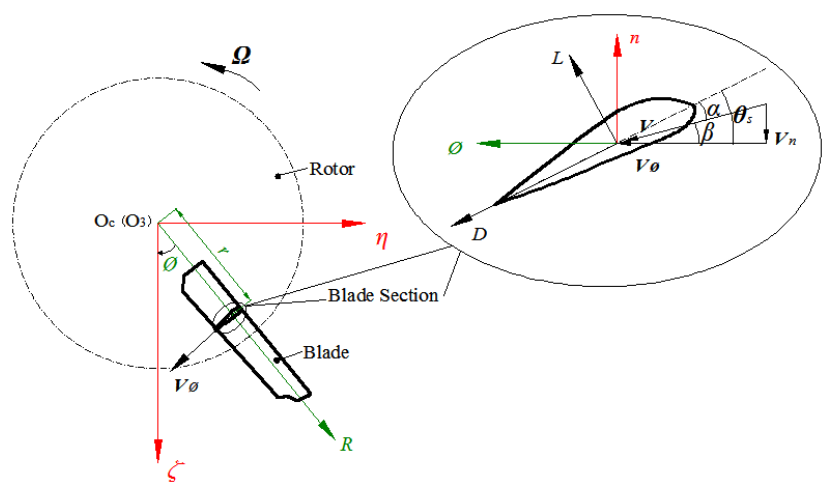

Top view of rotor, (a)

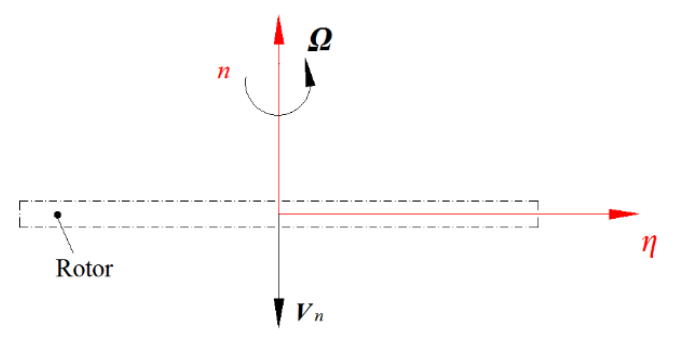

Main view of rotor, (b)

Fig. 4 Rotor disk coordinate

The distance from a certain blade element to rotor shaft was $r$, the circumferential angle was $\varphi$, the rotating speed was $\Omega$, rotor inflow velocity was $V_{\infty}$. Thus, the velocity of blade element was:

the tangential velocity $V_{\varphi}$ was:

$$
V_{\varphi}=V_{\varsigma} \sin \varphi-V_{\eta} \cos \varphi
$$

The total velocity $V$ was:

$$
V=\sqrt{V_{n}^{2}+\left(\Omega r+V_{\varphi}\right)^{2}} .
$$

The inflow angle $\beta$ was:

$$
\beta=\arctan \left(\frac{V_{n}}{\Omega r+V_{\varphi}}\right) .
$$

The angle of attack of blade element $\alpha$ was:

$$
\alpha=\theta_{s}-\beta
$$

Where: $\theta_{s}$ was collective pitch angle of the blade element.

\subsection{Calculate lift and drag forces on blade element}

According to angle of attack of blade elements, the Mach number, Reynolds number and the aerodynamic performance test data of the corresponding airfoil, the lift coefficient $C_{L}$ and drag coefficient $C_{D}$ was determined. However, this method is only applicable to a two-dimensional airfoil for it cannot reflect rotor blade tip loss for a threedimensional blade. This paper used a simple method to deal with the blade tip three-dimensional effect, that is, assuming 
when $r / R>0.96$, the blade lift coefficient $C_{L}=0$ and drag coefficient $C_{D}$ was still got from two-dimensional airfoil test data. So $4 \%$ tip of the blade produced only resistance but lift forces [11-12].

Lift and drag forces on the blade element was:

$$
\begin{aligned}
& L=\frac{1}{2} \rho V^{2} C_{\mathrm{L}} c d r, \\
& D=\frac{1}{2} \rho V^{2} C_{\mathrm{D}} c d r .
\end{aligned}
$$

Where: $c$ was chord length of blade, $d r$ was length of blade element along spanwise direction.

Coordinate transformation to rotor disk cylindrical coordinates:

$$
\left[\begin{array}{l}
F_{x} \\
F_{F}
\end{array}\right]=\left[\begin{array}{cc}
\cos b & -\sin b \\
\sin b & \cos b
\end{array}\right]\left[\begin{array}{l}
L \\
D
\end{array}\right] .,
$$
coordinate:

Coordinate transformation to rotor disk Cartesian

$$
\begin{aligned}
& F_{\xi}=F_{\phi} \sin \phi, \\
& F_{\eta}=-F_{\phi} \cos \phi .
\end{aligned}
$$

\subsection{Transformation to computational coordinate}

The three forces $F_{\xi}, F_{\eta}$ and $F_{n}$, which were components of lift and drag on blade element, were transformed to computational domain coordinate:

$$
\begin{aligned}
& {\left[\begin{array}{l}
F_{x} \\
F_{y} \\
F_{z}
\end{array}\right]=T^{\prime}\left[\begin{array}{c}
F_{\xi} \\
F_{\eta} \\
F_{n}
\end{array}\right],} \\
& T^{\prime}=\left[\begin{array}{ccc}
\cos B & 0 & -\sin B \\
-\sin A \times \sin B & \cos A & -\sin A \times \cos B \\
\cos A \times \sin B & \sin A & \cos A \times \cos B
\end{array}\right] .
\end{aligned}
$$

\subsection{Calculate momentum source}

The effect of rotor on surrounding air was distributed to elements, including time domain distribution and spatial domain distribution. In time domain, the pressure difference between the upper and lower surface of rotor was averaged over a rotation period, thus the unsteady flow was treated as a constant one. In spatial domain, the rotor was managed to a thin cylinder which has only five layers of prismatic grid, and then the effect of blade on surrounding fluid was averaged along circumferential direction to obtain average aerodynamic forces on every grid cell on rotor. To get distribution forces on element, the above calculated averaged forces were divided by volume of the grid, namely the momentum source.

$$
\begin{aligned}
& S_{x}=\frac{F_{x}}{\Delta V} \frac{\Delta S}{2 \pi r \cdot \mathrm{d} r} k . \\
& S_{y}=\frac{F_{y}}{\Delta V} \frac{\Delta S}{2 \pi r \cdot \mathrm{d} r} k . \\
& S_{z}=\frac{F_{z}}{\Delta V} \frac{\Delta S}{2 \pi r \cdot \mathrm{d} r} k .
\end{aligned}
$$

Where: $\Delta S$ was area of bottom surface of a prismatic element, $\Delta V$ was volume of element, $k$ was number of blades of the rotor. Then, momentum source was added to momentum equation, where air was considered as Newtonian fluid, to calculate aerodynamic effect of rotor on surrounding flow field [13].

$$
\nabla(\rho V V)=-\nabla P+\mu \nabla^{2} V+S
$$

Besides, the normal flow field, exclusive of rotor domain, was calculated by normal, compressible and threedimensional Reynolds averaged N-S equations.

$$
\nabla(\rho V V)=-\nabla P+\mu \nabla^{2} V
$$

\section{Case study}

\subsection{Geometry model}

In order to validate the calculation model proposed in this paper, a three-dimensional model of anti-torque system was built according to [1], shown in Fig. 5. The model consists of CC tail boom, variable pitch fan and thruster (Fig. 6). The fan, put inside of the tail boom and connected to engine shaft, sucked air into the tail boom and regulated pressurization by means of variation, which provided power for the whole anti-torque system. There were two slots on the tail boom, through which air jetted out and met rotor wake to form circulation control effect to produce a part of the lateral force. In calculation, the width of slots equal to sum of two slots. The remaining air continued to go backward and finally thrusted from thruster on end of tail boom to form an additional lateral force. Specific geometry parameters are shown in Table 1.

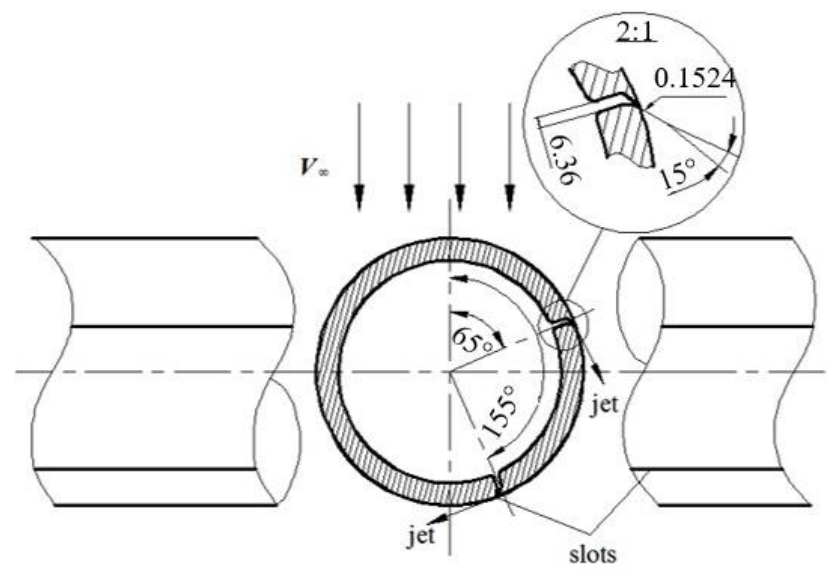

Fig. 5 Model for experiment in Ref. 1 


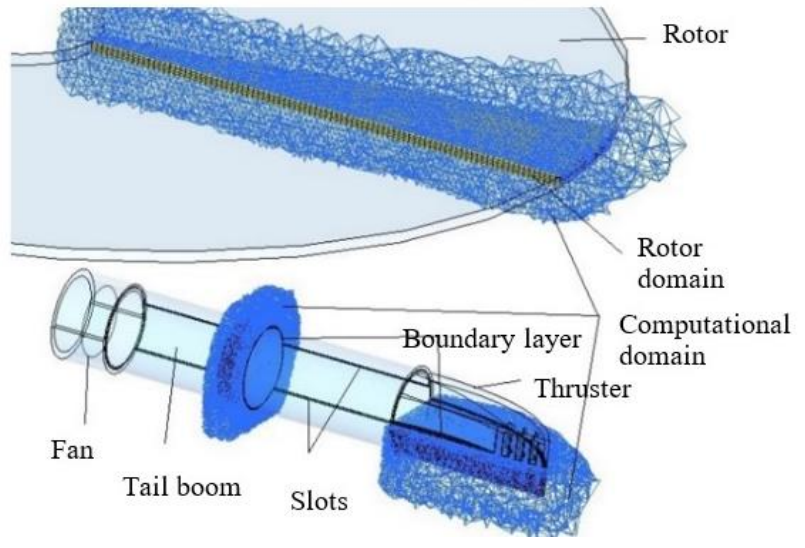

Fig. 6 Meshes of anti-torque system

Table 1

Geometry parameters of model

\begin{tabular}{|c|c|}
\hline Parameter & Value \\
\hline Diameter of rotor $D(\mathrm{~mm})$ & 2200 \\
\hline Length of tail boom $L_{\mathrm{t}}(\mathrm{mm})$ & 609.6 \\
\hline Length of each slot $L_{\mathrm{s}}(\mathrm{mm})$ & 609.6 \\
\hline Outside diameter of tail boom $D_{\mathrm{t}}(\mathrm{mm})$ & 152.4 \\
\hline Inside diameter of tail boom $d_{\mathrm{t}}(\mathrm{mm})$ & 127 \\
\hline Width of slots $h(\mathrm{~mm})$ & 0.1524 \\
\hline Inflow velocity $V_{0}(\mathrm{~m} / \mathrm{s})$ & 17.9 \\
\hline $\begin{array}{c}\text { The angle between each slot and } \\
\text { inflow } \theta\left({ }^{\circ}\right)\end{array}$ & 65 and 155 \\
\hline Diameter of fan $D_{\mathrm{f}}(\mathrm{mm})$ & 120 \\
\hline
\end{tabular}

\subsection{Meshes and boundary conditions}

The computational domain was established according to the model: the thruster jet flow equals to zero and the lateral force on anti-torque system was calculated in this case study. The domain was divided into two parts. One was rotor domain with momentum source, the other was common computational domain, shown in Fig. 6.

As the rotor head produces no lift, its effect on surrounding flow field was omitted and a circular shaped rotor domain established. Momentum source was loaded to calculate the aerodynamic characteristics of rotor wake.

A square external computational domain was established external of the anti-torque system. The side length of the domain was $8 D$ ( $D$ is diameter of rotor). When the far field boundary length is over $6 D$, the length of computational domain does not affect calculation results, see Fig. 7.

Due to geometry complexity of the model, the adaptable unstructured tetrahedral meshes were used [14]. Boundary layer on tail boom, slots and thruster was meshed. The first layer was about $0.0001 D_{\mathrm{t}}\left(D_{\mathrm{t}}\right.$ was external diameter of tail boom). The meshes on slots were refined and size function was set to make near wall grid gradually expand to sparse grids with a constant expansion ratio to fill the computation domain [15]. Thus the boundary layer flow was well captured and number of grids was reduced to improve computational efficiency. The mesh quantity was about 4,806,926.

For internal flow, a fan was built, which was a twodimensional disk, at the flow entrance of tail boom to offer pressurization once air come through the grids. Assuming that the fan power was sufficient, the pressurization was constant and the influence of flow separation and shock wave on blade was without consideration.

$$
P_{1}=P+\Delta p
$$

For external flow, rotor took in surrounding air and formed rotor wake, which was just the inflow for tail boom. The bottom face of the computational domain was calculated as pressure outlet and the other five surfaces were pressure inlet. The boundary condition of tail boom and thruster was no slip wall.

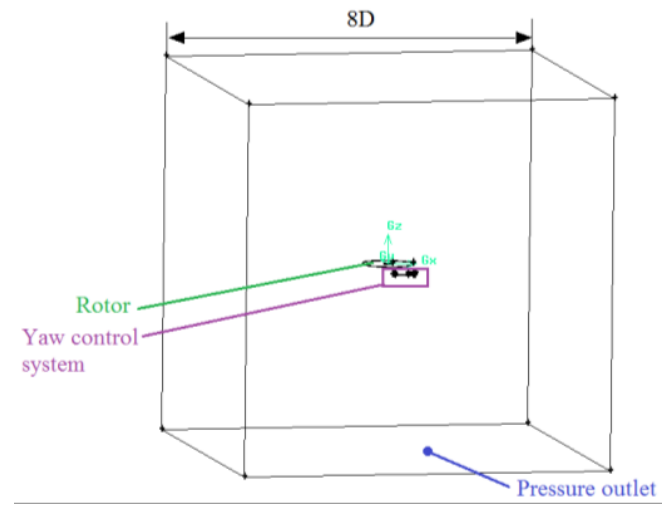

Fig. 7 Boundary conditions of computational domain

The steady, compressible and three-dimensional Reynolds averaged N-S equation [16] was solved under general curvilinear coordinates by iteration, and the density based coupled implicit solver was used.

The control equations were discrete by finite volume methods. For better accuracy, density and convection term was calculated by second order upwind. The adverse pressure gradient boundary layer and wall jet flow was calculated by S-A turbulence model. The properties of all units were initialized by initial conditions of the defined flow field before iteration. Simple method was used to solve the control equations for computational domain and rotor domain with momentum source.

\section{Model validation and analysis}

The Intel Xeon E5-1630 workstation (dominant frequency $3.7 \mathrm{GHz}$, memory $32 \mathrm{G}$ ) was used for calculation and 26 hours cost for the results.

The streamline of the whole field is shown in Fig. 8. The streamline of rotor reflected swirl and twist effect of rotor wake. The inflow of tail boom passed the pressurization fan, then a part of the air flow jetted from the slots and met the rotor wake to form circulation control effect, while the other part jetted out from thruster.

Fig. 9 shows static pressure distribution on section of the middle part of tail boom. Zone near stagnation point formed a high-pressure region. It is remarkable that the position of stagnation point was not just right above the tail boom, but tilted an angle of about 5 degrees, which just validated swirl and twist effect of the rotor wake. The jet flow from slots re-energized the boundary to delay flow separation and formed a low pressure region. The differential pressure between two sides of the tail boom formed the lateral force on CC tail boom.

The variation of lateral force coefficient $C_{y}$ with the change of momentum coefficient $C_{\mu}$ was calculated in 
this paper, which was contrasted with experimental data, shown in Table 2. Where:

$$
C_{y}=\frac{F_{1}}{\frac{1}{2} \rho V_{\infty}^{2} D_{t}} .
$$

Where: $\rho$ is density of air, $V_{\infty}$ is the far field flow velocity (rotor wake velocity), $D_{t}$ is diameter of tail boom section.

The momentum coefficient $C_{\mu}$ is defined as:

$$
C_{\mu}=2 \frac{\rho_{\mathrm{j}}}{\rho_{\infty}} \frac{h}{D_{t}}\left(\frac{V_{\mathrm{j}}}{V_{\infty}}\right)^{2} .
$$

Where: $\rho_{j}$ is density of jet air, $\rho_{\infty}$ is density of far field flow (rotor wake), $h$ is width of slots (width of sum of two slots), $D_{\mathrm{t}}$ is diameter of tail boom section, $V_{j}$ is velocity of jet air, $V_{\infty}$ is velocity of far flow field (rotor wake).

For anti-torque system with fixed structural parameters, the momentum coefficient $C_{\mu}$ varies with fan pressure jump, and thus the lateral force. When the momentum coefficient $C_{\mu}$ varies from 0.1 to 0.5 , changing rule of lateral force coefficient $C_{y}$ is shown in Fig. 10.

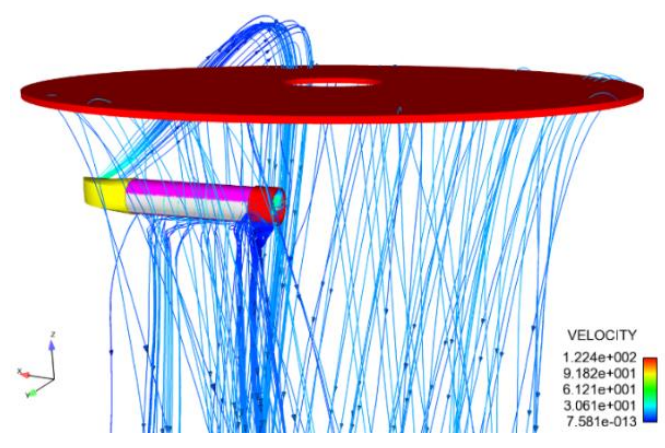

Fig. 8 Streamline of the flow field in hover

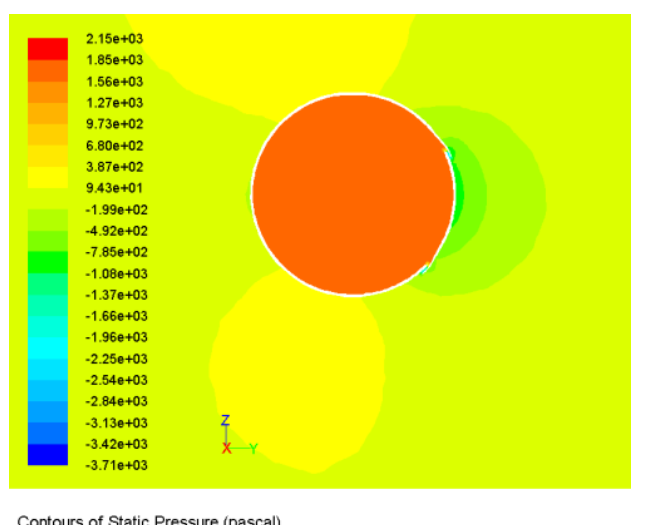

Fig. 9 Static pressure on section of tail boom

Table 2

Contrast between calculation data and experimental data

\begin{tabular}{|c|c|c|c|c|c|c|}
\hline \multicolumn{5}{|c|}{ Parameters } & \multicolumn{5}{c|}{ Value } \\
\hline Momentum coefficient $C_{\mu}$ & 0.1 & 0.2 & 0.3 & 0.4 & 0.5 \\
\hline \multirow{2}{*}{ Lateral force coefficient $C_{y}$} & Experimental data & 1.12 & 4.98 & 5.68 & 5.98 & 6.51 \\
\cline { 2 - 8 } & Calculation data & 0.84 & 4.41 & 5.17 & 5.96 & 6.5 \\
\hline Relative error & $25 \%$ & $11.4 \%$ & $8.98 \%$ & $0.33 \%$ & $0.15 \%$ \\
\hline
\end{tabular}

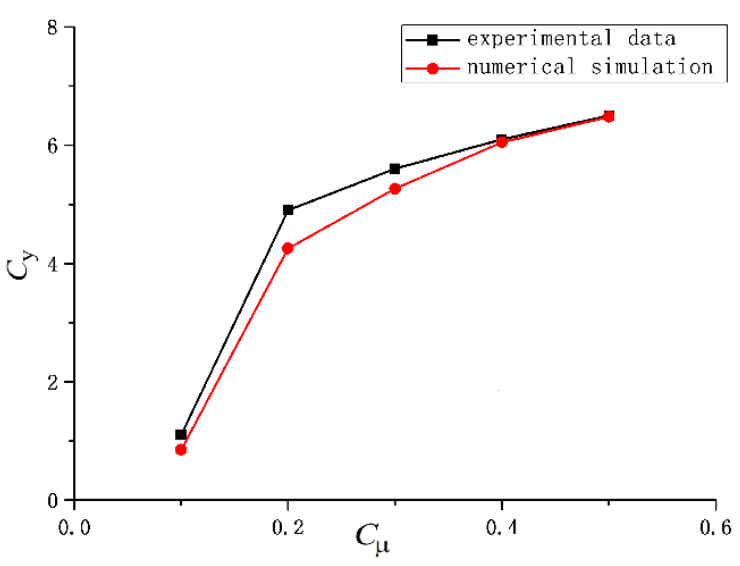

Fig. 10 Regulation of lateral force coefficient $C_{y}$ varied with momentum coefficient $C_{\mu}$

The variation tendency of lateral force coefficient $C_{y}$ with momentum coefficient $C_{\mu}$ was same as experimental data [1]. With the increase of $C_{\mu}$, the lateral force coefficient $C_{y}$ increased gradually. When $C_{\mu}$ was greater than 0.2 , the growth rate of $C_{y}$ decreased. For certain anti-torque system with fixed structural parameters, the only way to increase $C_{\mu}$ is to improve the fan pressurization, that is, improve the power supply. However, in order to obtain balance of aerodynamic efficiency and cost, the general choice of $C_{\mu}$ was around 0.4 when design, same as [4] suggested. At this point, the calculation relative error of $C_{y}$ was only $0.85 \%$, the accuracy of calculation was acceptable. That validated that the model proposed in this paper could accurately calculate aerodynamic characteristics of anti-torque system.

\section{Numerical research on parameter affects}

The key components of anti-torque system consisted of tail boom, fan and thruster, and the structural characteristics of which directly affected the aerodynamic performance. To calculate the affect, this paper divided the models into three groups, A, B and C groups, and applied the modeling method proposed above. The parameters including length of tail boom, area of nozzle on thruster and fan pressurization.

\subsection{Length of tail boom}

Group A consisted of 5 models (specific parameters are shown in Table 3 ) and lateral force and moment generated by $\mathrm{CC}$ tail boom and thruster were calculated respectively. Where, the torque arm referred to the distance between force and the rotor shaft in lateral moment calculation. 
Model parameters of group A

\begin{tabular}{|c|c|c|c|}
\hline Models & $\begin{array}{c}\text { Length of } \\
\text { tail boom } \\
(\mathrm{mm})\end{array}$ & $\begin{array}{c}\text { Fan pres- } \\
\text { surization } \\
(\mathrm{Pa})\end{array}$ & $\begin{array}{c}S \text { (Nozzle } \\
\text { area/Area } \\
\text { of slots })\end{array}$ \\
\hline Model A1 & 550 & 2500 & 4 \\
\hline Model A2 & 650 & 2500 & 4 \\
\hline Model A3 & 750 & 2500 & 4 \\
\hline Model A4 & 850 & 2500 & 4 \\
\hline Model A5 & 950 & 2500 & 4 \\
\hline
\end{tabular}

The calculation results are shown in Fig. 11.

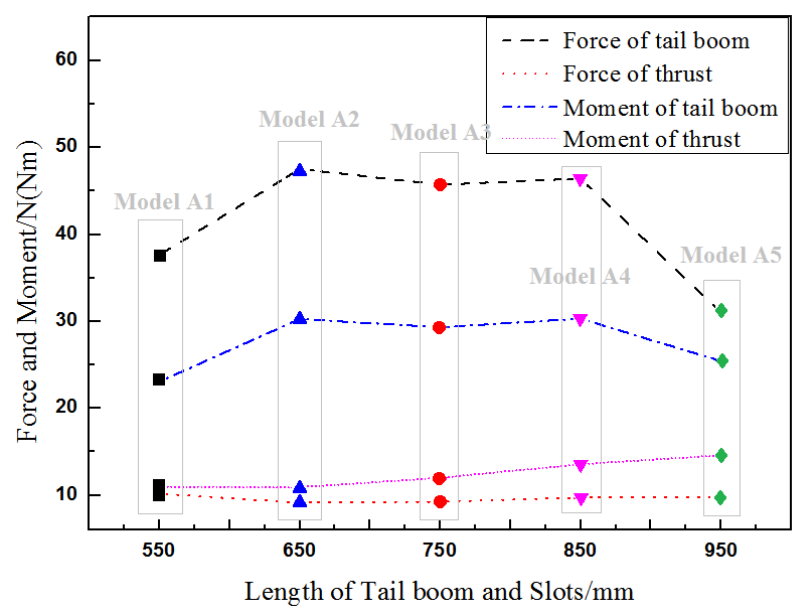

Fig. 11 Regulation of lateral force and moment varied with length of tail boom

From Fig. 11, following regularities can be found:

1. When the length of tail boom increased from $550 \mathrm{~mm}$ to $950 \mathrm{~mm}$, the curve of lateral force generated by thruster was relatively stable and with little fluctuation. That indicated that the aerodynamic characteristics of thruster was not sensitive to length of tail boom.

2. The fluctuation of curve that indicated lateral force generated by tail boom was greater. The curve increased first, then maintained stable and finally fell down. The force reached its peak when length of tail boom equalled to $650 \mathrm{~mm}$ and valley $950 \mathrm{~mm}$.

Once length of tail boom was too short, the circulation control effect was hardly fully formed before air flowed to thruster. At the same time, the wall friction and energy loss decreased. So the lateral force generated by thruster was greater. But overall, the efficiency of antitorque system was not satisfying. In contrast, if the length of tail boom was too long, the energy loss increased and led to decrease of jet velocity, momentum coefficient $C_{\mu}$ and thruster jet velocity. Therefore, the force generated by antitorque system was relatively small.

3. With the increase of length of tail boom, the torque arm of force increased. The variation tendency of moment was similar to force corresponding. When the tail boom length equalled to $950 \mathrm{~mm}$, tendency of moment decline eased.

To sum up, with the variation of length of tail boom, the moment generated by anti-torque system was relatively stable which increased first and then decreased, who reached maximum value when length of tail boom equalled to $850 \mathrm{~mm}$. The changing tendency of lateral force curve was similar to the former one, and reached the maximum value when length of tail boom equalled to $650 \mathrm{~mm}$.

\subsection{Nozzle area of thruster}

The area of nozzle was also an important factor to affect the aerodynamic characteristics of the anti-torque system, for what reason B group of models were proposed for calculation. The specific parameters are shown in Table 4.

Table 4

Model parameters of group B

\begin{tabular}{|c|c|c|c|}
\hline Models & $\begin{array}{c}\text { Length of } \\
\text { tail boom } \\
(\mathrm{mm})\end{array}$ & $\begin{array}{c}\text { Fan pres- } \\
\text { surization } \\
(\mathrm{Pa})\end{array}$ & $\begin{array}{c}S \text { (Nozzle } \\
\text { area/Area } \\
\text { of slots })\end{array}$ \\
\hline Model B1 & 550 & 2500 & 3 \\
\hline Model B2 & 550 & 2500 & 4 \\
\hline Model B3 & 550 & 2500 & 5 \\
\hline Model B4 & 550 & 2500 & 6 \\
\hline Model B5 & 550 & 2500 & 7 \\
\hline
\end{tabular}

The lateral force and moment generated by $\mathrm{CC}$ tail boom and thruster was calculated and shown in Fig. 12.

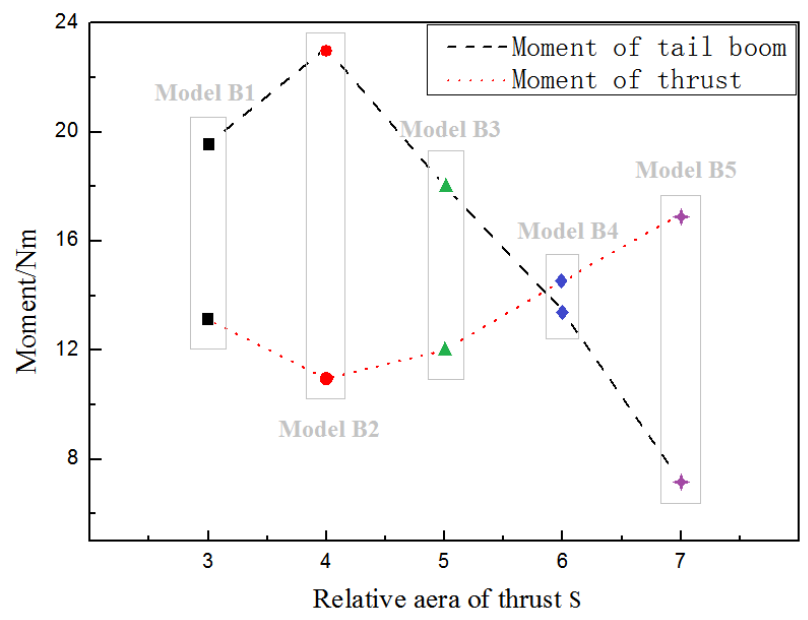

Fig. 12 Regulation of lateral moment varied with area of nozzle

From Fig. 12, following regularities were found:

1. When $S=4$, both two curves had an inflection point and the sum of lateral moment generated by tail boom and thruster reached its peak. That is, the aerodynamic efficiency of anti-torque system was the best.

2. When $S=3$, the lateral force generated by tail boom was relatively small while by thruster was great. For the area of nozzle reduced, the velocity of jet flow from thruster accelerated and formed stronger direct thrust force.

3. With the increase of nozzle area the majority of air tended to jet from nozzle instead of slots, which made efficiency of circulation control effect decreased and lateral moment curve formed a linear decline.

4. With the increase of nozzle area, lateral moment generated by thruster formed a linear rising.

To sum up, considering the comprehensive efficiency of tail boom and thruster, when $S=4$, the lateral moment reaches the maximum value. 


\subsection{Fan pressurization}

Fan is the power and inflow source for the whole anti-torque system which directly affects the momentum coefficient $C_{\mu}$. The influence of fan pressurization on antitorque system was calculated.

Nozzle area of $S=4$ and $S=7$ were chosen to build $\mathrm{C} 1$ and $\mathrm{C} 2$ group of models to calculate the impact of fan pressurization on anti-torque system. The specific parameters of $\mathrm{C} 1$ group are shown in Table 5 and $\mathrm{C} 2$ in Table 6.

Table 5

Model parameters of group $\mathrm{C} 1$

\begin{tabular}{|c|c|c|c|}
\hline Models & $\begin{array}{c}\text { Length of } \\
\text { tail } \\
\text { boom(mm) }\end{array}$ & $\begin{array}{c}\text { Fan pres- } \\
\text { suriza- } \\
\text { tion(Pa) }\end{array}$ & $\begin{array}{c}\text { S (Nozzle } \\
\text { area/Area } \\
\text { of slots) }\end{array}$ \\
\hline Model C11 & 550 & 1500 & 4 \\
\hline Model C12 & 550 & 2000 & 4 \\
\hline Model C13 & 550 & 2500 & 4 \\
\hline Model C14 & 550 & 3000 & 4 \\
\hline Model C15 & 550 & 3500 & 4 \\
\hline
\end{tabular}

Table 6

Model parameters of group C2

\begin{tabular}{|c|c|c|c|}
\hline Parameters & $\begin{array}{c}\text { Length of } \\
\text { tail } \\
\text { boom(mm) }\end{array}$ & $\begin{array}{c}\text { Fan pres- } \\
\text { suriza- } \\
\text { tion(Pa) }\end{array}$ & $\begin{array}{c}\text { S (Nozzle } \\
\text { area/Area } \\
\text { of slots) }\end{array}$ \\
\hline Model C21 & 550 & 1500 & 7 \\
\hline Model C22 & 550 & 2000 & 7 \\
\hline Model C23 & 550 & 2500 & 7 \\
\hline Model C24 & 550 & 3000 & 7 \\
\hline Model C25 & 550 & 3500 & 7 \\
\hline
\end{tabular}

14.

The calculation results are shown in Figs. 13 and found:

From Figs. 13 and 14, following regularities were

1. The lateral moment generated by tail boom and thruster increased with the increase of fan pressurization.

2. When $S=4$, moment generated by thruster linearly and gradually increased. Moment generated by tail boom increased rapidly first, and then slow down. That indicated that as fan power increased moment was not always increase but the efficiency continuous reduced.

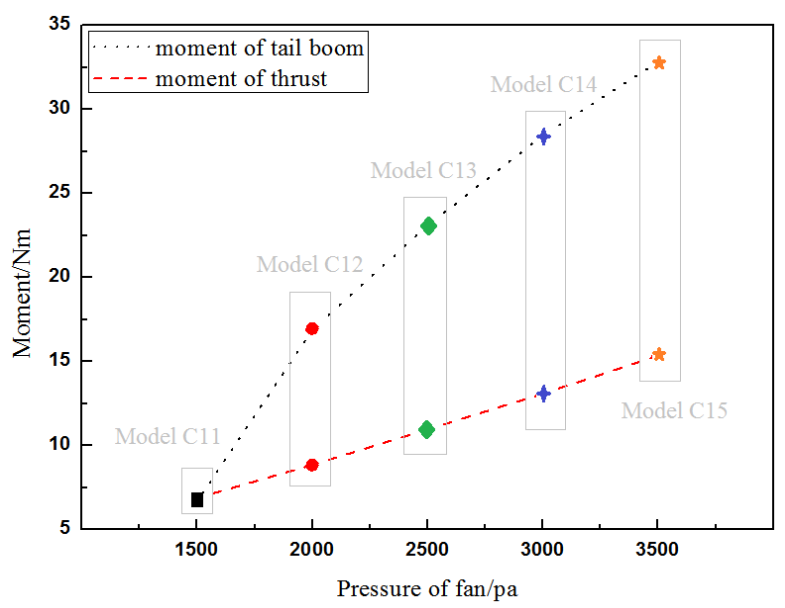

Fig. 13 Regulation of lateral moment varied with fan pressurization when $S=4$

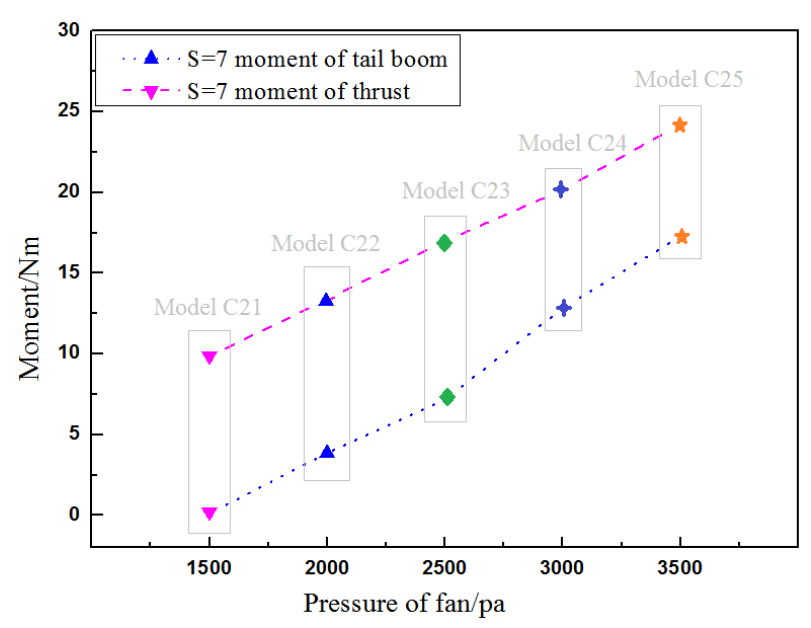

Fig. 14 Regulation of lateral moment varied with fan pressurization when $S=7$

3. When $S=7$, the variation law was similar to the former one. Fan pressurization was positively correlated with energy consumption. When the moment generated by anti-torque system just balanced the rotor anti-torque, it was the economic design point for fan pressurization.

4. The moment generated by tail boom was always greater when $S=4$ while thruster greater when $S=7$. When the nozzle area increased, more air flow tended to jet from thruster and led to thrust force increased. The pressure drop in tail boom accelerated and velocity of jet from slots reduced, and led to $\mathrm{CC}$ tail boom force decreased. Which also validated the conclusion that obtained from B group above.

To sum up, the lateral moment generated by antitorque system increased with fan pressurization. The aerodynamic efficiency of $S=4$ model was better than $S=7$.

\section{Conclusions}

A three-dimensional aerodynamic model for antitorque system of NOTAR based on finite volume methods was proposed in this paper. The model consisted of rotor, variable pitch fan, $\mathrm{CC}$ tail boom and thruster. The flow field of rotor domain was calculated by momentum source method and the normal, compressible and three-dimensional Reynolds averaged N-S equation was solved by the S-A turbulence model. The flow field of whole anti-torque system was obtained and validated by experimental data. Subsequently, parameter influence on the anti-torque system was calculated including length of tail boom, the area of nozzle and the fan pressurization. The main conclusions were as follows:

1. With the increase of length of tail boom, the lateral force and moment of the tail boom fluctuated while the thruster remain relatively stable. To gain better aerodynamic efficiency, the length of tail boom should be moderate. For the helicopter with rotor diameter of about $2200 \mathrm{~mm}$, the appropriate length of tail boom was about $650 \mathrm{~mm}-850 \mathrm{~mm}$.

2. The nozzle area of thruster had a significant influence on the aerodynamic efficiency of anti-torque system. When $\mathrm{S}=4$, it was better. 
3. As the fan pressurization increased, the lateral moment of the anti-torque system increased, while the fan power consumption also increasing rapidly. So it was necessary to balance economy and efficiency. For the helicopter with rotor diameter of about $2200 \mathrm{~mm}, 2500 \mathrm{~Pa}$ of the fan pressurization could meet the anti-torque amounts.

\section{Acknowledgements}

The authors wish to thank the program of "Research on danger Identification and Control Technology during Flight Training (0241501/2146903)" for funding for this Research Group.

\section{References}

1. Sampatacos, E. P.; Morger, K. M.; Logan, A. H. 1983. NOTAR: The Viable Alternative to a Tail Rotor. AIAA Aircraft Eesign, Systems and Technology Meeting. 1633 Broadway, New York AIAA: 1-8. http://dx.doi.org/10.2514/6.1983-2527.

2. Lockwood, V. E. 1960. Lift Generation of a Circular Cylinder by Tangential Blowing from Surface Slots. National Aeronautics and Space Administration D: 244:138.

3. Dionisio, F. A.; Nurick, A. 2001. Investigation of a Circulation Controlled Cylinder Using Adaptive Wall Wind Tunnel. Journal of Aircraft. 38(3). http://dx.doi.org/10.2514/2.2792.

4. Xiao ping, L.; Cheng lin, Z.; Hua Ming, W. 2001. Experimental Study of No Tail Rotor (NOTAR) Helicopter, Transactions of Nanjing University of Aeronautics and Astronautics 18(1):54-59.

http://dx.doi.org/10.3969/j.issn.10051120.2001.01.009.

5. Chao, Z. 2010. Research of Aerodynamic Characteristics to NOTAR Heading control system. Nanjing: Nanjing University of Aeronautics and Astronautics.

6. Velkoff. H. R.; Tung, C. 1991. Aerodynamic Design of a Coanda Induced Force Thruster Anti-torque System. Annual Forum of the American Helicopter Soceity, 1259-1274.

7. Holz. R.G.; Hassan, Ahmed, Reed \& Helen. 1992. 2$\mathrm{D}$ numerical model for predicting the aerodynamic performance of the NOTARTM system tailboom. 48th Annual Forum Proceedings of the American Helicopter Society, Washington DC, 1295-1305.

8. Holz. R. G.; Hassan. Ahmed A. 1994. Numerical Model for Circulation Control Flows. AIAA Journal 32(4): 701-707, 1994.

http://dx.doi.org/10.2514/3.12042.

9. Gross. A.; Fasel, H. F. 2006. RANS, URANS, and LES of Coanda Wall Jet Flows. 36th AIAA Fluid Dynamic Conference and Exhibit, San Francisco, California. 5-8. http://dx.doi.org/10.2514/6.2006-3371.

10. Meftah, S. M. A.; Lmine, B.; Lmine, O.; Adjlout, L. 2011. Numerical simulation of a flow around an unmanned aerial vehicle. Mechanika, 279(2):193-196. http://dx.doi.org/10.5755/j01.mech.17.2.339.
11. Rajagopalan, R.G.; Lim, C. K. 1991. Laminar Flow Analysis of a Rotor in Hover. Journal of the American Helicopter Society 36(1): 12-23.

https://doi.org/10.4050/JAHS.36.12.

12. Bo, W., Qi Jun, Z.; Guo Hua, X., 2008. Numerical Simulation for the flowfield of helicopter rotor/fuselage based upon Momentum-Source Method. Helicopter technique. 133(3):25-30.

http://dx.doi.org/10.3969/j.issn.1673-1220.2008.03.005.

13. Rajagopalan, R. G.; Mathur, S. R., 1993. Three dimensional analysis of a rotor in forward flight. Journal of the American Helicopter Society 38(3): 14-25. http://dx.doi.org/10.2514/6.1989-1815.

14. Henry, I.V.; Gerald, I.I.; Pertl, E.D.; Clarke, M. A.; Smith, J.E. 2011. CFD Analysis of a 15\% circulation controlled elliptical. International Journal of Research and Reviews in Computer Science 2(2): 334-339.

15. Bode, F.; Meslem, A.; Croitoru, C, 2013, Numerical simulation of a very low Reynolds cross-shaped jet. Mechanika 19(5):512-517. http://dx.doi.org/ 10.5755/j01.mech.19.5.5537.

16. Rui Heng, H. 2012. Research on wind tunnel wall correction methods for helicopter experiment. Nanjing: Nanjing University of Aeronautics and Astronautics.

\section{Chen, H. Cheng, P. Sun, C. H. Zhou}

\section{AN AERODYNAMIC CALCULATION MODEL FOR ANTI-TORQUE SYSTEM OF NOTAR}

\section{S u m m a r y}

The existing experimental methods and numerical models were difficult to get accurate aerodynamic characteristics of the anti-torque system of a NOTAR under rotor wake. To solve this problem, a new three-dimensional aerodynamic model with momentum source based on finite volume method was proposed in this paper. By means of time domain equalization and spatial interpolation, the complicated dynamic meshes on blade were replaced by the nonblade fixed rotor domain with momentum source. And the model was calculated by steady, compressible and three-dimensional Reynolds averaged N-S equation. In this paper, a typical NOTAR was took for research, the aerodynamic characteristics including flow field and variation regularity of lateral force with momentum coefficient of anti-torque system during hover condition was obtained by applying the above computational model, and the accuracy of which was verified by corresponding experimental data. In addition, the model was also used to analyze the key factors that influence working condition of the tail boom, including length of tail boom, area of nozzle and fan pressurization. And the curves of variation regularity were given. The model and work in this paper could provide reference for further research and design on anti-torque system for NOTAR.

Keywords: calculation model; CFD; circulation control; momentum source; NOTAR. 